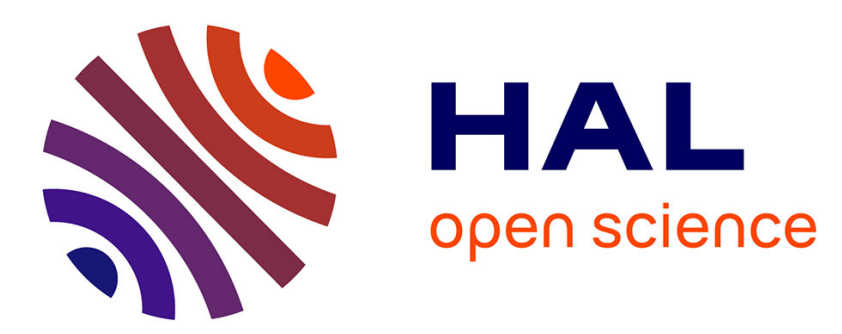

\title{
Stabilizer thickness profiles in polyethylene pipes transporting drinking water disinfected by bleach
}

Xavier Colin, Jacques Verdu, Benjamin Rabaud

\section{To cite this version:}

Xavier Colin, Jacques Verdu, Benjamin Rabaud. Stabilizer thickness profiles in polyethylene pipes transporting drinking water disinfected by bleach. Polymer Engineering and Science, 2011, 51 (8), pp.1541-1549. 10.1002/pen.21902 . hal-02299331

\section{HAL Id: hal-02299331 \\ https://hal.science/hal-02299331}

Submitted on 27 Sep 2019

HAL is a multi-disciplinary open access archive for the deposit and dissemination of scientific research documents, whether they are published or not. The documents may come from teaching and research institutions in France or abroad, or from public or private research centers.
L'archive ouverte pluridisciplinaire HAL, est destinée au dépôt et à la diffusion de documents scientifiques de niveau recherche, publiés ou non, émanant des établissements d'enseignement et de recherche français ou étrangers, des laboratoires publics ou privés. 
archives-ouvertes

\section{Stabilizer thickness profiles in polyethylene pipes transporting drinking water disinfected by bleach}

Xavier Colin, Jacques Verdu, Benjamin Rabaud

\section{To cite this version:}

Xavier Colin, Jacques Verdu, Benjamin Rabaud. Stabilizer thickness profiles in polyethylene pipes transporting drinking water disinfected by bleach. Polymer Engineering and Science, Wiley-Blackwell, 2011, Volume 51 (Issue 8), pp.Pages 1541-1549. hal-02299331

\section{HAL Id: hal-02299331 \\ https: / hal.archives-ouvertes.fr/hal-02299331}

Submitted on 27 Sep 2019

HAL is a multi-disciplinary open access archive for the deposit and dissemination of scientific research documents, whether they are published or not. The documents may come from teaching and research institutions in France or abroad, or from public or private research centers.
L'archive ouverte pluridisciplinaire HAL, est destinée au dépôt et à la diffusion de documents scientifiques de niveau recherche, publiés ou non, émanant des établissements d'enseignement et de recherche français ou étrangers, des laboratoires publics ou privés. 


\title{
Stabilizer Thickness Profiles in Polyethylene Pipes Transporting Drinking Water Disinfected by Bleach
}

\author{
X. Colin, ${ }^{1}$ J. Verdu, ${ }^{1}$ B. Rabaud ${ }^{2}$ \\ ${ }^{1}$ Arts et Metiers ParisTech, 151 Boulevard de l'Hôpital, Paris, France \\ ${ }^{2}$ Suez-Environnement, CIRSEE, Le Pecq, France
}

Polyethylene connection pipes of wall thickness ranging from 3.0 to $4.5 \mathrm{~mm}$, used for $0,5,9,12$, and 18 years in the French network of drinking water disinfected by bleach, have been analyzed. The stabilizer thickness profiles reveal that bleach destroys the stabilizer in a superficial layer of about $0.5 \mathrm{~mm}$ depth at the water-polymer interface. In the rest of the wall, stabilizer is lost by physical processes, i.e., transport by diffusion into the bulk, extraction at the water-polymer interface, and evaporation at the polymer-air interface. The whole loss kinetics is governed by extraction and evaporation. The classical scheme for evaporation-diffusion process has been used to model physical loss processes, but with boundary conditions different from the literature ones. Concerning chemical aspects, some mechanisms proposed in the literature are criticized. The identification of the bleach reactive species remains an open question. POLYM. ENG. SCl., 51:1541-1549, 2011.

\section{INTRODUCTION}

A polyethylene (PE) pipe transporting water at temperature $T$ and pressure $p$ (inducing a hoop stress $\sigma$ ) is expected to undergo failure after a finite time $t_{\mathrm{F}}$. Here, only stresses significantly lower than a critical value of the order of $10 \mathrm{MPa}$, covering the whole pressure range used in practice, will be considered. In this stress range, pipes always perish by brittle fracture. At temperatures typically lower than $50^{\circ} \mathrm{C}$, in the absence of radical reagents, fracture results from purely physical processes. The stress dependence of lifetime can be approximated by a power law:

$$
t_{\mathrm{F}}=A(T) \sigma^{-m}
$$

where $A(T)$ is a factor depending on temperature and polymer structure. The exponent $m$ was of the order of 3

Correspondence to: X. Colin; e-mail: xavier.colin@paris.ensam.fr DOI 10.1002/pen.21902 in former linear PE (LPE) generations [1, 2], about 30 in cross-linked PE (XPE) [3] and perhaps also in the last LPE generation.

Practitioners use rather the inverse relationship:

$$
\sigma=[A(T)]^{\frac{1}{m}} t_{\mathrm{F}}^{\frac{-1}{m}}
$$

Linear graphs are obtained in logarithm coordinates:

$$
\log \sigma=B(T)-\frac{1}{m} \log t_{\mathrm{F}}
$$

where $B(T)=\frac{1}{m} \log A(T)$.

Among structural factors involved in $A(T)$, molar mass distribution is especially important because it governs many properties playing a key role in fracture, for instance: chain disentanglement rate in the amorphous phase [4, 5] and in craze fibrils [2, 6], tie-chains concentration [7, 8], and interlamellar spacing [9, 10], the last one being found to determine the regime of fracture in tension [10].

It seems thus that, if, in addition to mechanical loading, the polymer undergoes a chain scission process, $A(T)$ is expected to decrease, the curve $\log \sigma=f\left(\log t_{\mathrm{F}}\right)$ is expected to become an almost vertical straight line [11], as experimentally observed [11, 12], and, thus, the lifetime is expected to shorten.

There is, to our knowledge, only one possible cause of chain scission for PE in the relatively soft use conditions of water pipes: radical chain oxidation. The main chain scission precursors, in the context of low temperature oxidation, are secondary alkoxy radicals, which can abstract hydrogens to give alcohols, but also rearrange to give a chain $(\beta)$ scission. Alkoxy radicals can result from hydroperoxide decomposition or can escape from the cage in nonterminating bimolecular combinations of peroxy radicals [13]. Oxidation can be initiated by hydroperoxide decomposition. This process can 
predominate at high temperature, but it would be very slow at temperatures lower than $50^{\circ} \mathrm{C}$. A recent kinetic study of the low-temperature oxidation of unstabilized PE [14] lead to estimate a value of about 20 years for the induction time at ambient temperature (the time to embrittlement would be of the same order). Indeed, it would be considerably longer in the presence of stabilizers, as confirmed by extrapolations of induction times determined at high temperature [15]. At low temperature, however, initiation of radical chain oxidation can also be due to the polymer attack by water disinfectants. These latter, which are aimed to destroy organic substances by radical processes, cannot be totally selective. Furthermore, even in the case where their reactivity toward PE was negligible, they would attack phenolic antioxidants of which the functional hydrogen is a thousand times more reactive than methylenic hydrogens of PE, and, thus, they would have a negative indirect effect on pipe durability.

In addition to chemical consumption by reaction with reactive species coming from PE oxidation (peroxy radicals) or from the disinfectants, stabilizers can be lost by physical processes, essentially extraction by water at the water-polymer interface and evaporation at the polymerair interface. This is the reason why it is now well recognized that the analysis of antioxidant thickness profiles is of key importance to understand pipe ageing processes [16-20]. The simplest experimental approach, in such investigations, consists to machine thin slabs at various depths in the pipe wall thickness and to determine their oxidation induction time (OIT) at high temperature, for instance at $190^{\circ} \mathrm{C}$ or $200^{\circ} \mathrm{C}$ using isothermal differential scanning calorimetry. It can be assumed, at least, in a first approach that the induction time for phenolic stabilizers is proportional to the residual stabilizer concentration [21, 22]. Stabilizer profiles in pipe walls have been already reported, but essentially in the context of accelerated ageing [16-20]. In the case of natural ageing, isolated data are available [19], but systematic studies are scarce for obvious economic reasons and also because significant data can be obtained only when the pipe history is known.

In France, premature failures due to chlorine dioxide (DOC), at the beginning of the 2000s, created favorable conditions for such systematic investigations. A first set of articles was dedicated to a study of DOC effects [19, $23,24]$. This article is devoted to the study of samples taken in the part of the French network of drinkable water disinfected by bleach.

\section{EXPERIMENTAL}

Connection pipes of PE80 or PE63 generation, of 30$45 \mathrm{~mm}$ diameter and respectively $3.0-4.5 \mathrm{~mm}$ wall thickness, having various manufacturer origins, were taken in several parts of the French network of drinking water disinfected by bleach or DOC, or free of disinfectant. Their characteristics obey the French standard: NF EN 12201. They present the following characteristics: $2.0-2.5 \%$ by weight of carbon black; melting point, $T_{m} \approx 120-130^{\circ} \mathrm{C}$; crystallinity ratio, $X_{c}=35-45 \%$; weight average molar mass, $M_{w}=100-150 \mathrm{~kg} \mathrm{~mol}^{-1}$; and OIT at $190^{\circ} \mathrm{C}, t_{i}=$ $165 \pm 15 \mathrm{~min}$.

Pipes were machined and slabs of $0.5 \mathrm{~mm}$ thickness were taken at various depths in the pipe wall. Slabs were cut into samples of 5-10 mg and analyzed by differential scanning calorimetry to determine the local OIT $t_{i}$ at $190^{\circ} \mathrm{C}$ in a pure oxygen flow of $50 \mathrm{ml} \mathrm{min}^{-1}$. The local residual stabilizer concentration was determined according to the classical relationship:

$$
\frac{t_{i}}{t_{i 0}}=\frac{[\mathrm{AH}]}{[\mathrm{AH}]_{0}}
$$

where $t_{i 0}$ and $t_{i}$, and $[\mathrm{AH}]_{0}$ and $[\mathrm{AH}]$ are, respectively, OITs and stabilizer concentrations before and after aging.

\section{RESULTS}

Examples of induction time profiles for pipes taken in the French network of drinking water disinfected by bleach are shown in Fig. 1. In each profile, the first point on the left side corresponds to the superficial layer in contact with water, and the last point on the right side corresponds to the outer superficial layer (OSL). These profiles reveal the existence of three distinct zones: the inner superficial layer (ISL), the core zone (CZ), and the OSL. They call for the following comments:

Pipes were of various sources. Virgin samples elaborated in 2005 [24] were arbitrarily chosen to establish the initial profile seen in Fig. 1. This profile is flat in most of the wall thickness except in OSL where a relative decrease of about $25 \%$ is observed. This feature is systematically observed in virgin pipes [25, 26]. It reveals some stabilizer loss by oxidation and/or evaporation dur-

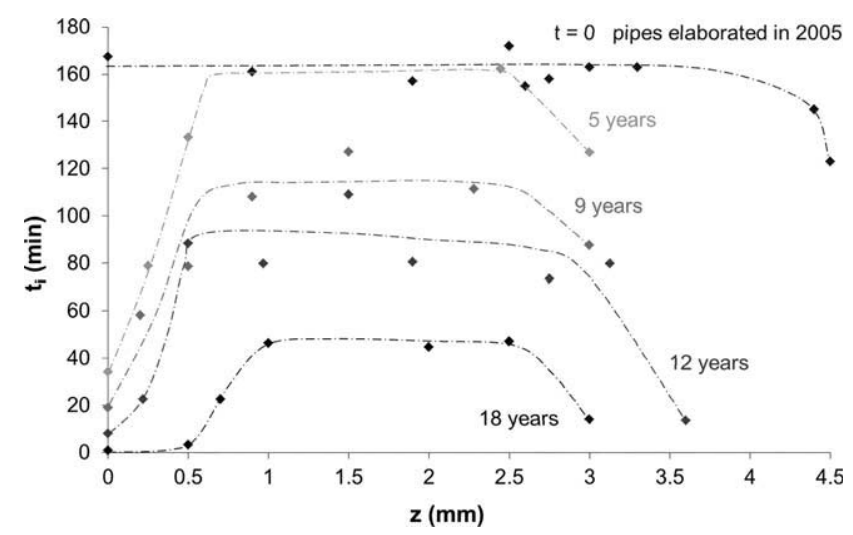

FIG. 1. Typical profiles of oxidation induction time after natural aging in bleach-disinfected water at an average temperature of $\approx 20^{\circ} \mathrm{C}$. The numbers in the figure indicate the pipe age in years. Virgin PE pipes elaborated in 2005 were arbitrarily chosen to establish the initial profile. 


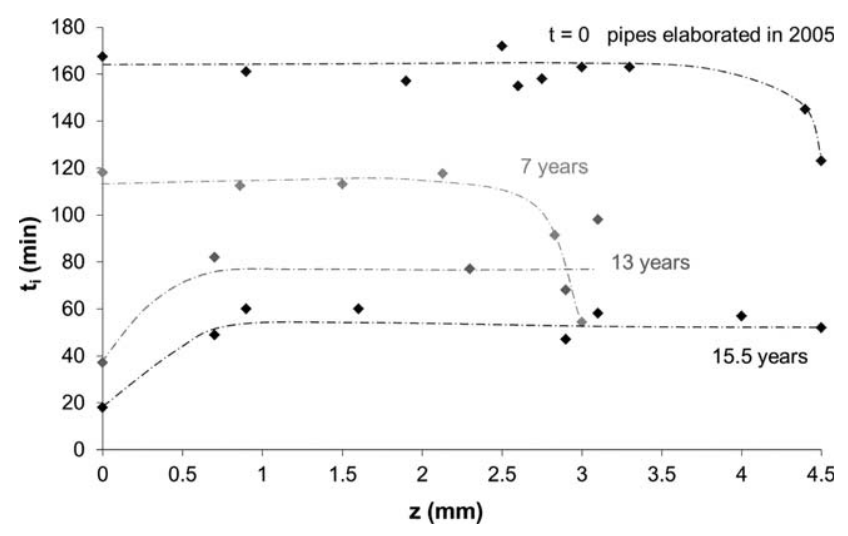

FIG. 2. Typical profiles of oxidation induction time after natural aging in disinfectant-free water at an average temperature of $\approx 15^{\circ} \mathrm{C}$. The numbers in the figure indicate the pipe age in years. Virgin PE pipes elaborated in 2005 were arbitrarily chosen to establish the initial profile.

ing pipe processing. In ISL and CZ regions, the stabilizer distribution seems homogeneous. The induction time in these regions can vary between about 150 and $200 \mathrm{~min}$ depending of the pipe origin.

Ageing effects can be summarized as follows: The stabilizer concentration decreases in all the regions, but in a different way in ISL and in the rest of the wall. In CZ, practically no change is observed in a first period of about 5 years. Then, the profile remains flat and undergoes a slow translation toward low values. OSL behaves practically as CZ. If a difference in the rates of induction time decrease exists, it is within measurement incertitudes. In ISL, the decrease is faster, and its rate is a decreasing function of the distance to surface. No doubt, in this region, the stabilizer is consumed by reactive species coming from water.

The shape of the profiles can be compared with those of pipes taken in nondisinfected networks (Fig. 2) or in networks disinfected by DOC (Fig. 3). Virgin samples elaborated in 2005 [24] were arbitrarily chosen to establish the initial profile seen in both figures. No clear differences appear in $\mathrm{CZ}$ and OSL regions. In contrast, profiles are significantly different in the ISL one. The rates of stabilizer depletion in this zone are in the order:

$$
\text { DOC }>>\text { bleach }>\text { non disinfected water }
$$

In the case of DOC, ISL reaches rapidly an asymptotic depth of the order of $1 \mathrm{~mm}$, and the transition between ISL and CZ is almost vertical, very sharp, and its depth is practically independent of ageing conditions [19, 24]. In the case of nondisinfected water, ISL remains undifferentiated of $\mathrm{CZ}$ in the first years of exposure. Then, a gradient appears, but it remains considerably less marked than in disinfected networks. Pipes exposed in bleach-disinfected water have an intermediary behavior. The transition between ISL and CZ is more progressive than with DOC, and it is impossible to establish, from these results, whether the depth of ISL reaches or not an asymptotic value.

\section{DISCUSSION}

Globally, the explanations proposed in our previous articles about DOC effects [19, 23, 24] remain valid here: The reactive agent coming from bleach acts only in ISL, as shown by comparison of Figs. 1 (bleach) and 2 (no disinfectant). The comparison between Figs. 1 and 3 (DOC) shows that bleach is considerably less aggressive than DOC. This latter destroys totally the antioxidant in a thin superficial layer, in less than 8 years, whereas the antioxidant concentration remains measurable after 12 years in the case of bleach-disinfected water.

In the case of DOC, the depth of ISL tends toward an asymptotic value of the order of $1 \mathrm{~mm}$, almost independent of DOC concentration in water. This feature can be explained by the fact that DOC is also consumed by its reaction with $\mathrm{PE}$ :

$$
\mathrm{O}=\mathrm{Cl}-\mathrm{O}^{\mathrm{o}}+-\mathrm{CH}_{2}-\rightarrow \mathrm{O}=\mathrm{Cl}-\mathrm{OH}+-\mathrm{CH}^{\mathrm{o}}-\quad\left(k_{\mathrm{DOC}}\right)
$$

After total antioxidant destruction, DOC is consumed only by this reaction, and its local consumption rate is given by:

$$
\frac{d[\mathrm{DOC}]}{d t}=-k_{\mathrm{DOC}}[\mathrm{DOC}]\left[\mathrm{CH}_{2}\right]=-K[\mathrm{DOC}]
$$

At reasonably low conversions (before total PE embrittlement), the methylene concentration can be considered constant, and the system behaves as a first-order reaction of rate constant $K=k_{\mathrm{DOC}}\left[\mathrm{CH}_{2}\right]$. In such cases, the depth of reacted layer is expected to be independent of the

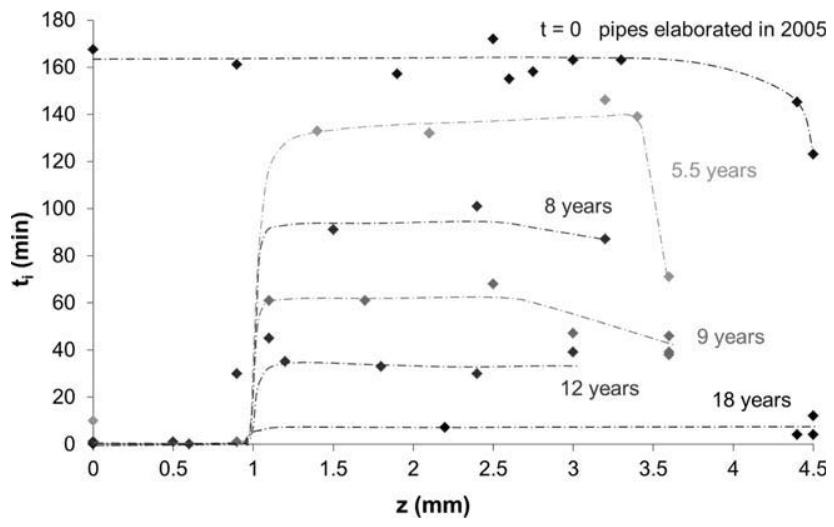

FIG. 3. Typical profiles of oxidation induction time after natural aging in DOC-disinfected water at an average temperature of $\approx 12-14^{\circ} \mathrm{C}$. The numbers in the figure indicate the pipe age in years. Virgin PE pipes elaborated in 2005 were arbitrarily chosen to establish the initial profile. 


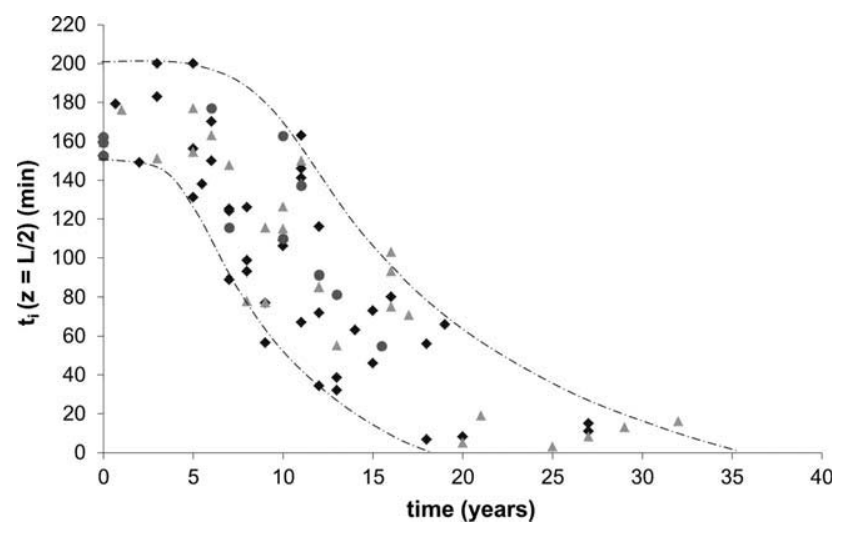

FIG. 4. Oxidation induction time in the middle of the wall $(z=L / 2)$ against exposure time for natural aging in bleach- $(\boldsymbol{A})$ and DOC-disinfected water $(\bullet)$ and disinfectant-free water $(\boldsymbol{O})$ for pipes used in the French water distribution network.

reagent concentration in the environment, and its order of magnitude is given by [27]:

$$
L_{\infty} \approx\left(\frac{D}{K}\right)^{1 / 2}
$$

where $D$ is the coefficient of reagent (here DOC) diffusion.

It seems difficult to conclude, from Fig. 1, whether bleach behaves or not as DOC because the timescales of stabilizer disappearance in ISL and CZ are not different enough. However, it seems probable that antioxidant is destroyed by a radical process, and it would be difficult to imagine a radical reagent that would have a so high selectivity as it would destroy antioxidant without attacking PE.

Interesting observations can be made about the changes observed in CZ and OSL. The flatness of the profiles indicates clearly that the stabilizer diffusivity is high enough, compared with the losses at the surface, to redistribute quasi homogeneously the stabilizer in CZ. In OSL, losses result from evaporation and extraction by water. In Fig. 4, the induction time in the middle of the wall, i.e., on the plateau, was plotted against the reduced time of exposure for all the measurements made whatever the disinfection mode was (none, bleach, or DOC). A common kinetic behavior clearly appears: the induction time remains first almost constant for a few years, and, then, it decreases in a sigmoidal way to vanish after $18-35$ years. The time to reach the half of the initial value ranges between about 7 and 17 years. The scatter is surprisingly low if we consider the variety of pipe origins, temperatures, disinfectant natures, and concentrations. It is tempting, from this result, to made two hypotheses: First, chemical consumption plays a little role in the global antioxidant loss phenomenon. Second, there are very little differences in the transport properties of the stabilizers used by the various pipe manufacturers involved in this study.
Thus, a model aimed to predict the changes in antioxidant concentration profiles must involve two components: The first one dedicated to simulate physical transport, loss processes being almost the same for DOC and bleach. The second one, dedicated to simulate chemical processes, could be significantly different.

Let us first consider antioxidant loss kinetics independently of chemical consumption. Evaporation kinetic laws are generally based on two assumptions:

When the polymer is saturated by the stabilizer, the loss rate of this latter $r_{\mathrm{eS}}$ (number $N$ of stabilizer moles lost per area and time units) is equal to the evaporation rate of pure stabilizer, i.e., independent of the matrix nature.

Below the saturation level, the loss rate $r_{\mathrm{e}}$ is proportional to the stabilizer concentration $[\mathrm{AH}]_{\text {surf }}$ in the superficial layer:

$$
r_{\mathrm{e}}=-\frac{d N}{d t}=-r_{\mathrm{eS}} \frac{[\mathrm{AH}]_{\mathrm{surf}}}{[\mathrm{AH}]_{\mathrm{S}}} \quad\left(\text { in } \mathrm{mol} / \mathrm{m}^{2} / \mathrm{s}\right)
$$

where $[\mathrm{AH}]_{\mathrm{S}}$ is the stabilizer concentration at saturation.

When evaporation controls loss kinetics (see later), the stabilizer is homogeneously destroyed into the whole sample volume, and the stabilizer depletion in the polymer matrix is given by:

$$
\frac{d[\mathrm{AH}]}{d t}=-\frac{r_{\mathrm{e}}}{L}=-\beta[\mathrm{AH}]
$$

where $\beta=\frac{r_{\mathrm{SS}}}{L[\mathrm{AH}]_{\mathrm{S}}}\left(\mathrm{s}^{-1}\right)$ is the first-order rate constant, and $L$ is the sample thickness.

There are relatively abundant literature data obtained on thin samples and showing that additive evaporation from polyolefins is effectively a first-order process (see for instance Ref. [28]). Lundback et al. [25, 26] consider rather the loss rate $r_{\mathrm{e}}$ and a "rate constant" $F_{0}$ defined by:

$$
F_{0}=\frac{r_{\mathrm{eS}}}{[\mathrm{AH}]_{\mathrm{S}}}=\beta L \quad(\text { in } \mathrm{m} / \mathrm{s})
$$

These authors reported $F_{0}$ values for two stabilizers of relatively close molar masses: a thiobisphenol (Irganox $1081, M=353 \mathrm{~g} \mathrm{~mol}^{-1}$ ) and a methylene bisphenol (Lowinox 22M46, $M=335 \mathrm{~g} \mathrm{~mol}^{-1}$ ) in two distinct matrices: LPE and branched PE (BPE) at $90^{\circ} \mathrm{C}$ and $95^{\circ} \mathrm{C}$. They found relative close $F_{0}$ values for a given matrix, for instance $(2.1-4.5) \times 10^{-9} \mathrm{~m} \mathrm{~s}^{-1}$ in LPE, but a significant difference between both matrices $\left((3-13) \times 10^{-10} \mathrm{~m} \mathrm{~s}^{-1}\right.$ for BPE), which seems to invalidate the first assumption on which evaporation kinetic law is based. These values were obtained with a sample of $2.7 \mathrm{~mm}$ thickness, which leads to $\beta$ values ranging from $7.8 \times 10^{-6}$ to $16.7 \times$ $10^{-6} \mathrm{~s}^{-1}$ for LPE and from $1.1 \times 10^{-7}$ to $4.8 \times 10^{-7} \mathrm{~s}^{-1}$ for BPE.

Using a coupled transport-reaction kinetic model for PE pipes of 3.0-4.5 mm wall thickness, used in French 
drinking water network for various durations, Colin et al. [29] determined $\beta$ and $D$ values by an inverse approach and found $\beta=10^{-10} \mathrm{~s}^{-1}$ and $D=9.7 \times 10^{-17} \mathrm{~m}^{2} \mathrm{~s}^{-1}$ at $15^{\circ} \mathrm{C}$. The $D$ value corresponds to a stabilizer of relatively high molar mass, presumably Irganox $1010(M=$ $1178 \mathrm{~g} \mathrm{~mol}^{-1}$ ) for which $D \approx 10^{-16} \mathrm{~m}^{2} \mathrm{~s}^{-1}$ at $15^{\circ} \mathrm{C}$ [30]. Nuclear magnetic resonance analysis confirmed that the stabilizer was effectively Irganox 1010.

For the pipes under study, in these conditions, $F_{0} \approx 3$ $\times 10^{-13} \mathrm{~m} \mathrm{~s}^{-1}$ and $F_{0} / D \approx 3000 \mathrm{~m}^{-1}$ against from 4800 to $7800 \mathrm{~m}^{-1}$ for the precited bisphenols at $90-95^{\circ} \mathrm{C}$ whatever the PE matrix was $[25,26]$.

Considering the differences in molecular size and in temperature, and the various sources of incertitude, these values of $F_{0} / D$ are surprisingly close and seem to indicate that evaporation and diffusion are governed in the same way by the same structural factors.

A kinetic model for the diffusion-evaporation process has been elaborated by Crank [31] and then used by Calvert and Billingham in the case of polyolefin-stabilizer systems [32, 33]. A dimensionless quantity $\Phi$ can be defined from this theory as the ratio of diffusion and evaporation characteristic times:

$$
\Phi=\frac{\beta L^{2}}{D}=\frac{F_{0} L}{D}
$$

Schematically, if $\Phi \gg 1$, the process is diffusion controlled, and there are marked concentration gradients in the sample thickness. On the contrary, if $\Phi \ll 1$, the process is evaporation controlled, and the stabilizer concentration profile is flat. According to Calvert and Billingham $[32,33]$, there would be a transition domain:

$$
0.6 \leq \Phi \leq 10
$$

For samples of about $3 \mathrm{~mm}$ thickness, the values of $F_{0} / D$ reported above lead to $\Phi$ values of the order of 10 [29] or from 13 to $21[25,26]$. From a recent compilation of literature data [34], we find a relatively sharp transition domain at $\Phi \approx 15 \pm 4$. These data carry relatively strong incertitudes, but two clear observations can be made: For bisphenols at $90-95^{\circ} \mathrm{C}$, as for Irganox 1010 at $15^{\circ} \mathrm{C}$, in PE samples of about $3 \mathrm{~mm}$ thick, stabilizer loss is evaporation controlled. However, in both cases, the system is close to the transition between evaporation controlled and diffusion controlled kinetic regimes.

It is too soon to generalize such a behavior, but the results reported here seem to indicate an interesting trend: The evaporation rate constant $\beta$ and the coefficient of diffusion $D$ would vary almost proportionally with the antioxidant structure and the temperature of exposure. If this trend was confirmed in the future, the predominance of diffusion or evaporation control would depend almost exclusively of the sample thickness.

Extraction by water receives the same kinetic treatment as evaporation. Extraction rate constants are slightly higher than evaporation ones [24-26], but remain of the same order of magnitude. Lundback et al. $[25,26]$ have shown that extraction is faster in air than in nitrogen-bubbled water, and explained the difference by the fact that the stabilizer (Santonox R) is destroyed by oxidation in water. This difference is probably a characteristic of ageing tests made in stagnant water. Sophisticated models have been proposed to take into account hydrodynamic factors [35-37], but in the case under study of drinking water networks, it can be reasonably assumed that the stabilizer concentration in water is negligible.

For the elaboration of a kinetic model for stabilizer physical losses, all the authors start from a first-order law for evaporation and Fick's law for diffusion. The models differ essentially by the choice of the boundary conditions. For Lundback et al. [25, 26]:

$$
D_{\mathrm{AH}}\left(\frac{\partial[\mathrm{AH}]}{\partial z}\right)_{\text {surf }}=-F_{0}[\mathrm{AH}]_{\text {surf }}
$$

For Colin et al. [29]:

$$
D_{\mathrm{AH}}\left(\frac{\partial^{2}[\mathrm{AH}]}{\partial z^{2}}\right)_{\text {surf }}=-\beta[\mathrm{AH}]_{\mathrm{surf}}
$$

where the subscript "surf" indicates the superficial elementary layer.

Both equations seem to us questionable because they are rigorously valid only when $[\mathrm{AH}]_{\text {surf }}=0$ for flat concentration profiles. They can be replaced by:

$$
\left(\frac{d[\mathrm{AH}]}{d t}\right)_{\mathrm{surf}}=D_{\mathrm{AH}}\left(\frac{\partial^{2}[\mathrm{AH}]}{\partial z^{2}}\right)_{\text {surf }}-\beta[\mathrm{AH}]_{\text {surf }}
$$

The mode of numerical computation is detailed in the appendix.

Let us now consider chemical aspects. In the case of DOC, the phenolic stabilizer was consumed by two reactions: A direct reaction with DOC and the polymer stabilization process:

$$
\begin{array}{r}
\mathrm{PO}_{2}^{\mathrm{o}}+\mathrm{AH} \rightarrow \mathrm{POOH}+\text { inactive products }\left(k_{7}\right) \\
\mathrm{ClO}_{2}^{\mathrm{o}}+\mathrm{AH} \rightarrow \text { inactive products }\left(k_{8 d}\right)
\end{array}
$$

No stabilizer-water reaction was considered because water concentration into $\mathrm{PE}$ is too low to induce significant hydrolysis, and stabilizer concentration in water is negligible. The balance reaction for the stabilizer was then:

$$
\frac{d[\mathrm{AH}]}{d t}=D_{\mathrm{AH}} \frac{d^{2}[\mathrm{AH}]}{d z^{2}}-k_{7}\left[\mathrm{PO}_{2}^{\circ}\right][\mathrm{AH}]-k_{8 d}[\mathrm{DOC}][\mathrm{AH}]
$$

where $\mathrm{PO}_{2}^{\circ}$ comes from the radical chain oxidation of $\mathrm{PE}$. 
In the case of DOC, it was assumed that it is the DOC molecule itself, which penetrates into PE and reacts with the stabilizer and with the polymer. In the case of chlorine or bleach, the situation is more complicated because the chemistry of these systems in PE matrix is not totally elucidated. It is well known that, in water, three main strongly oxidizing species can be formed: $\mathrm{Cl}_{2}$ which predominates at $\mathrm{pH}<3, \mathrm{ClO}^{-}$which predominates at $\mathrm{pH}>7.5$, and $\mathrm{ClOH}$ which predominates at $3<\mathrm{pH}<7.5$ [38]. These species coexist with other ions: $\mathrm{Cl}^{-}, \mathrm{HO}^{-}$, and $\mathrm{ClO}_{3}^{-}$, and with radicals, especially $\mathrm{HO}^{\circ}$ and $\mathrm{ClO}^{\circ}$. In dark, when it is present, $\mathrm{Cl}_{2}$ can slowly dissociate into $\mathrm{Cl}^{\circ}$ radicals. Two factors impose a certain selectivity to these systems: the $\mathrm{pH}$ of water as seen above and the PE impermeability to ions. As a matter of fact, the very low polarity of PE disfavours the dissolution of highly polar species such as water and, a fortiori, ions. Among the remaining possible species, two have been envisaged: chlorine and hydroxyl radicals. Chlorine was considered as the reactive species by Gandek et al. [35], Dear and Mason [39], and Mittelman et al. [37]. As reported above, dichlorine must be present only in acidic media, and it must be totally absent or in a very low concentration in drinking water. Furthermore, it is expected to be a reactive species through its dissociation into $\mathrm{Cl}^{\circ}$ radicals. This reaction is very slow in dark and could eventually be the rate-controlling step in the process of stabilizer destruction. Chlorine will be, thus, kept as candidate for reactive species only if there is no better alternative. Hydroxyl radicals formation would result from a mechanism proposed by Holst [40]:

$$
\begin{gathered}
\mathrm{ClOH}+\mathrm{ClO}^{-} \rightarrow \mathrm{ClO}^{\circ}+\mathrm{Cl}^{-}+\mathrm{HO}^{\circ} \\
\mathrm{HO}^{\circ}+\mathrm{ClO}^{-} \rightarrow \mathrm{ClO}^{\circ}+\mathrm{HO}^{-} \\
\mathrm{ClO}^{\circ}+\mathrm{ClO}^{-}+\mathrm{HO}^{-} \rightarrow 2 \mathrm{Cl}^{-}+\mathrm{O}_{2}+\mathrm{HO}^{\circ}
\end{gathered}
$$

Their formation is thus favored in the domain of $\mathrm{ClOH}$ and $\mathrm{ClO}^{-}$coexistence, i.e., essentially at $\mathrm{pH}=7.5 \pm 1.5$ [38], which largely coincides with the $\mathrm{pH}$ domain of drinking water. Several authors have assumed that polymer degradation in the presence of disinfectants is essentially due to $\mathrm{HO}^{\circ}$ radicals [41-44]. However, $\mathrm{HO}^{\circ}$ radicals are extremely reactive, even with saturated alkanes as PE. They are, thus, expected to be consumed in a very thin superficial layer, probably of micrometric thickness or thinner. The assumption of reaction with $\mathrm{HO}^{\circ}$ radicals seems to us difficult to reconcile with the observed depth of stabilizer chemical attack $(\approx 0.5 \mathrm{~mm})$. However, as for chlorine, we lack of quantitative arguments to reject it definitively.

$\mathrm{ClO}^{\circ}$ radicals seem to us the best candidates. They are formed in the same $\mathrm{pH}$ interval as $\mathrm{HO}^{\circ}$ radicals, and they are many orders of magnitude less reactive, so that they could eventually explain the observed stabilizer concentration profiles in ISL.

There is a long way before the elaboration of a kinetic model for stabilizer loss in the presence of bleach-disin- fected water. Future research on this topic must involve the following steps:

1. Identify unequivocally the reactive species, essentially from comparative studies of model systems. Chlorine can be generated in gas phase, hydroxyl radicals can be generated from hydrogen peroxide, etc.

2. Determine the concentration of reactive species in water for the conditions (temperature, $\mathrm{pH}$, and bleach concentration) under study.

3. Determine the solubility of reactive species in PE, which is a challenging objective for species such as $\mathrm{HO}^{\circ}$ and $\mathrm{ClO}^{\circ}$. It will be perhaps necessary to estimate this solubility by theoretical methods.

4. Determine the diffusivity of reactive species in PE. Estimations can be made from comparisons; for instance, $\mathrm{ClO}^{\circ}$ is presumably intermediary between $\mathrm{Cl}_{2}$ and $\mathrm{O}_{2}$ of which the diffusivities are known.

5. Determine the rate constants of stabilizer and PE reactions with the reactive species. If the above physical parameters are known with a sufficient precision, rate constants can be determined from stabilizer concentration profiles using an inverse approach [29].

\section{CONCLUSIONS}

Stabilizer concentration profiles in the wall thickness of PE pipes exposed to water disinfected by bleach have been determined for pipes used in the French network of drinking water for durations up to 18 years. Comparisons with results obtained, in the same period, in network parts not disinfected or disinfected by DOC lead to the following observations:

Most of the stabilizer loss is due to physical processes, i.e., diffusion-evaporation, mainly in evaporation-controlled kinetic regime. This part of the stabilizer loss, predominant in $\mathrm{CZ}$ and OSL, i.e., in $2 / 3$ to $3 / 4$ of the whole pipe wall thickness, is almost independent of the disinfectant nature. Modeling of this component can be performed using a first-order kinetic law for evaporation and Fick's law for diffusion. Results obtained on strongly different systems (bisphenols at $90-95^{\circ} \mathrm{C}$ or Irganox 1010 at $15^{\circ} \mathrm{C}$ ) seem to indicate that the ratio between evaporation rate constant and diffusion coefficient undergoes only slight variations from a stabilizer to another and from a temperature to another. This result needs, however, to be confirmed.

To conclude about physical loss, we are not very far from a reliable model to predict antioxidant concentration profiles in CZ and OSL. In ISL, the stabilizer is destroyed by reaction with the disinfectant or a reaction product of this latter. Bleach attacks the stabilizer, but at a rate considerably lower than DOC. In samples of 3.0-4.5 mm thickness, stabilizer has not totally disappeared in the superficial layer (of $0.5 \mathrm{~mm}$ thick) after 18 years of exposure, so that it is impossible to appreciate the rate of an eventual disinfectant-PE reaction contrarily to the case of DOC.

The chemistry of bleach-PE interaction is not totally understood. Several assumptions have been examined, but a supplementary research is needed to fully elucidate the mechanisms and to elaborate a suitable kinetic model. 


\section{APPENDIX}

Let us discretize the pipe wall (of thickness $L \approx$ some $\mathrm{mm}$ ) into a high number of thin elemental layers (of typical thickness $\Delta z \approx$ some $\mu \mathrm{m}$ ). Let us consider a given elemental layer $(i)$ located at the depth $z$ beneath the inner (IS, $z=0$ ) or outer surface (OS, $z=L$ ). At least three different cases can be distinguished, and are schematized in Figs. A1-A3: Case (a) represents antioxidant transport by diffusion in CZ; case (b) represents antioxidant transport by diffusion plus evaporation (or water extraction) at IS or OS; and case (c) represents antioxidant transport by diffusion at IS or OS coated by an impermeable layer.

In each case, the global stabilizer flux density $J$ (expressed in mol m $\mathrm{m}^{-2} \mathrm{~s}^{-1}$ ) crossing the median plane of the elemental layer $(i)$ is the algebraic sum of two opposite elemental flux densities: one $J^{+}$in the arbitrarily chosen direction of stabilizer diffusion (to the left) and, thus, crossing the boundary $(-)$ separating the elemental layers $(i-1)$ and $(i)$, and the other $J^{-}$in the opposite direction to antioxidant diffusion (to the right) and, thus, crossing the boundary $(+)$ separating the elemental layers $(i)$ and $(i+1)$.

$$
J=\frac{1}{S} \frac{d n_{i}}{d t}=J^{+}-J^{-}
$$

where $n_{i}$ is the number of moles of stabilizer molecules crossing the median plane (i) and $\mathrm{S}$ the surface of the median plane of the elemental layer (i).

Case (a): In $C Z(0<z<L)$

The application of Fick's first law to each elemental flux density leads to:

$$
\begin{aligned}
& J^{+}=-D \frac{C_{i}-C_{i-1}}{\Delta z} \\
& J^{-}=-D \frac{C_{i+1}-C_{i}}{\Delta z}
\end{aligned}
$$

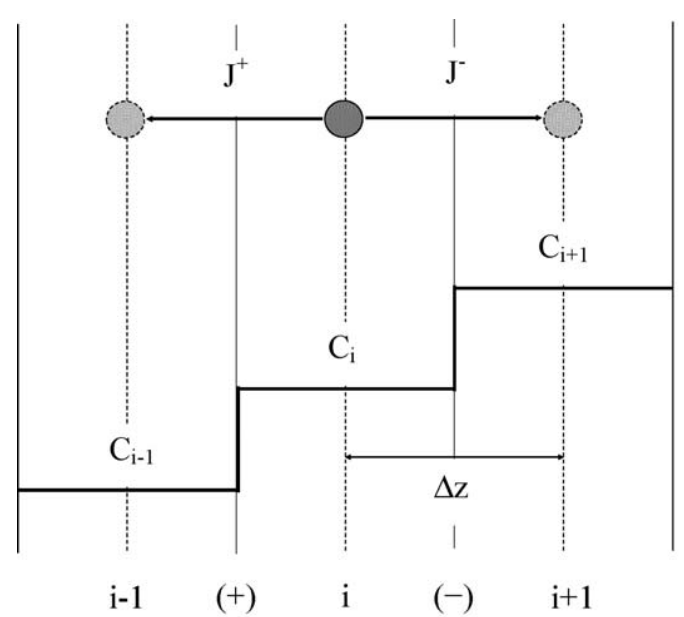

FIG. A1. Schematic of antioxidant transport by diffusion in CZ.

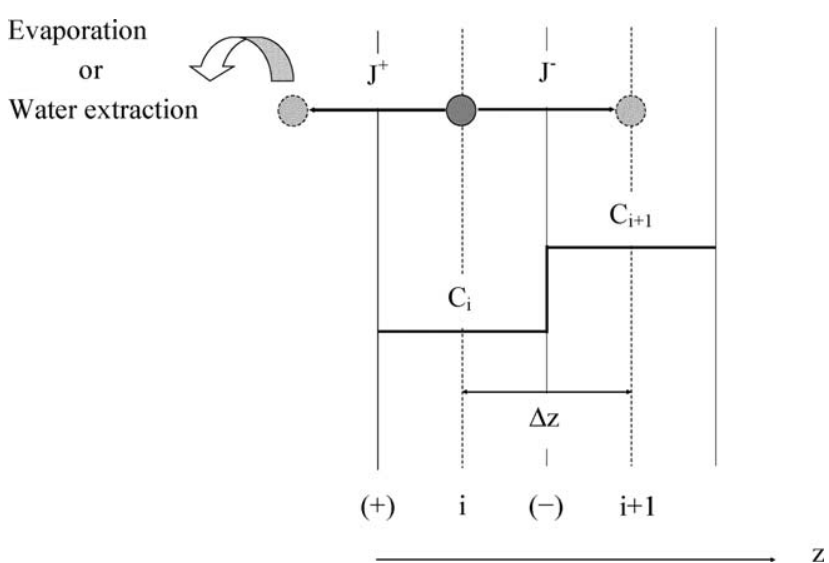

FIG. A2. Schematic of the antioxidant transport by diffusion plus evaporation (or water extraction) at IS or OS.

where $D$ is the coefficient of antioxidant diffusivity, expressed in $\mathrm{m}^{2} \mathrm{~s}^{-1}$.

Thus, Eq. Al becomes:

$$
\begin{array}{r}
J=\frac{1}{S} \frac{d n_{i}}{d t}=D \frac{C_{i+1}-2 C_{i}+C_{i-1}}{\Delta z} \\
\Rightarrow \Delta z \frac{d C_{i}}{d t}=D \frac{C_{i+1}-2 C_{i}+C_{i-1}}{\Delta z} \\
\Rightarrow \frac{d C_{i}}{d t}=D \frac{C_{i+1}-2 C_{i}+C_{i-1}}{\Delta z^{2}}
\end{array}
$$

This last expression corresponds to Fick's second law:

$$
\frac{d C}{d t}=D \frac{\partial^{2} C}{\partial z^{2}}
$$

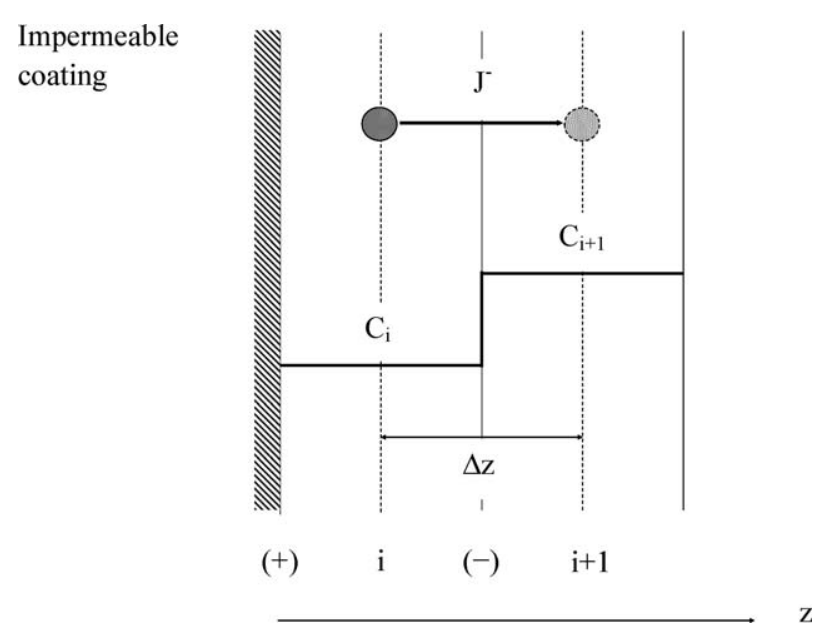

FIG. A3. Schematic of the antioxidant transport by diffusion at IS or OS coated by an impermeable layer. 
Case (b): At IS or $O S(z \rightarrow 0)$

Eq. A3 remains valid. According to Billingham and Calvert [32, 33], the stabilizer evaporation or water extraction can be expressed by:

$$
J^{+}=-\beta C_{i} \Delta z
$$

where $\beta$ is the "exchange coefficient" at the polymer-air or water-polymer interface, expressed in $s^{1}$.

Thus, Eq. Al becomes:

$$
\begin{aligned}
& J=\frac{1}{S} \frac{d n_{i}}{d t}=-\beta C_{i} \Delta z+D \frac{C_{i+1}-C_{i}}{\Delta z} \\
& \Rightarrow \Delta z \frac{d C_{i}}{d t}=-\beta C_{i} \Delta z+D \frac{C_{i+1}-C_{i}}{\Delta z} \\
& \\
& \Rightarrow \frac{d C_{i}}{d t}=-\beta C_{i}+D \frac{C_{i+1}-C_{i}}{\Delta z^{2}}
\end{aligned}
$$

This last expression can be rewritten in the following general form:

$$
\frac{d C}{d t}=-\beta C+\frac{D}{\Delta z} \frac{\partial C}{\partial z}
$$

where $\beta=0$ if the surface is coated by an impermeable layer, and $\beta>0$ otherwise.

Case (c): At IS or OS Coated by an Impermeable Layer $(z \rightarrow 0)$

Eq. A3 remains valid yet. But, stabilizer molecules cannot cross interface $(+)$, so that:

$$
J^{+}=0
$$

Thus, Eq. Al becomes:

$$
\frac{d C_{i}}{d t}=D \frac{C_{i+1}-C_{i}}{\Delta z^{2}}
$$

This last expression can be rewritten in the following general form:

$$
\frac{d C}{d t}=\frac{D}{\Delta z} \frac{\partial C}{\partial z}
$$

\section{REFERENCES}

1. Y. Lu and N. Brown, J. Mater. Sci., 25, 29 (1990).

2. C.J.G. Plummer, "Microdeformation and Fracture in Semicrystalline Polymers," in Mechanical Properties of Polymers Based on Nanostructure and Morphology, G.H. Michler and F.-J. Balta Calleja, Eds., Taylor and Francis, Boca Raton, FL, Chap. 6, 215-244 (2005).

3. C. Munier, E. Gaillard-Devaux, A. Tcharktchi, and J. Verdu, J. Mater. Sci., 37, 4159 (2002).

4. A. Lustiger, "Environmental Stress Cracking: The Phenomenon and Its Utility," in Failure of Plastics, V. Brostow and R. Corneliussen, Eds., Hanser Publishers, Munich, Chap. 16, 314-316 (1986).
5. H.-H. Kausch, N. Heymans, C.F. Plummer, and P. Decroly, "Matériaux Polymères: Propriétés Mécaniques et Physiques," in Traité des Matériaux, Vol. 14, Presses Polytechniques et Universitaires Romandes, Lausanne, 374-376 (2001).

6. Y.L. Huang and N. Brown, J. Polym. Sci.: Polym. Phys. Ed., 29, 129 (1991).

7. A. Lustiger and R.L. Markham, Polymer, 24, 1647 (1983).

8. R. Seguela, J. Polym. Sci.: Polym. Phys. Ed., 43, 1729 (2005).

9. T. Trankner, M. Hedenqvist, and U.W. Gedde, Polym. Eng. Sci., 34, 1581 (1994).

10. M.S. Hedenqvist, Morphology and Morphology Sensitive Properties of Polyethylene: Fracture Behaviour and Diffusivity, PhD Thesis, Department of Polymer Technology, Royal Institute of Technology, Stockholm (1995).

11. U.W. Gedde, J. Viebke, H. Leijstrom, and M. Ifwarson, Polym. Eng. Sci., 34, 1773 (1994).

12. R.W. Lang, A. Stern, and G. Doerner, Die Angew. Makromol. Chem., 247, 131 (1997).

13. N. Khelidj, X. Colin, L. Audouin, J. Verdu, C. Monchy-Leroy, and V. Prunier, Polym. Degrad. Stab., 91, 1598 (2006).

14. X. Colin, C. Monchy-Leroy, L. Audouin, and J. Verdu, Nucl. Instrum. Methods Phys. Res. B, 265, 251 (2007).

15. E. Richaud, C. Monchy-Leroy, X. Colin, L. Audouin, and J. Verdu, Polym. Degrad. Stab., 94, 2004 (2009).

16. T.S. Gill, R.G. Knapp, S.W. Bradley, and W.L. Bradley, Plast. Rubber Compos., 28, 303 (1999).

17. J.P. Dear and N.S. Mason, Polym. Polym. Compos., 9, 1 (2001).

18. J. Hassinen, M. Lundback, M. Ifwarson, and U.W. Gedde, Polym. Degrad. Stab., 84, 261 (2004).

19. X. Colin, L. Audouin, J. Verdu, M. Rozental-Evesque, F. Martin, and F. Bourgine, "Kinetic Modelling of the Ageing of Polyethylene Pipes for the Transport of Water Containing Disinfectants," in Proceedings of Plastic Pipes XIII, Washington, DC, October 2-5 (2006).

20. E.M. Hoang and D. Lowe, Polym. Degrad. Stab., 93, 1496 (2008).

21. J.B. Howard, Polym. Eng. Sci., 13, 429 (1973).

22. J. Viebke and U.W. Gedde, Polym. Eng. Sci., 37, 896 (1997).

23. X. Colin, L. Audouin, J. Verdu, M. Rozental-Evesque, B. Rabaud, F. Martin, and F. Bourgine, Polym. Eng. Sci., 49, 1429 (2009).

24. X. Colin, L. Audouin, J. Verdu, M. Rozental-Evesque, B. Rabaud, F. Martin, and F. Bourgine, Polym. Eng. Sci., 49, 1642 (2009).

25. M. Lundback, C. Strandberg, A.-C. Albertsson, M.S. Hedenqvist, and U.W. Gedde, Polym. Degrad. Stab., 91, 1071 (2006).

26. M. Lundback, M.S. Hedenqvist, A. Mattozzi, and U.W. Gedde, Polym. Degrad. Stab., 91, 1571 (2006).

27. L. Audouin, V. Langlois, J. Verdu, and J.C.M. De Bruijn, J. Mater. Sci., 29, 569 (1994).

28. J. Durmis, M. Karvas, P. Caucik, and J. Holisk, Eur. Polym. J., 11, 219 (1975).

29. X. Colin, L. Audouin, and J. Verdu, Macromol. Symp., 286, 81 (2009). 
30. J.Y. Moisan, Eur. Polym. J., 16, 979 (1980).

31. J. Crank, The Mathematics of Diffusion, 2nd ed., Oxford University Press, Oxford (1975).

32. P.D. Calvert and N.C. Billingham, J. Appl. Polym. Sci., 24, 357 (1979).

33. N.C. Billingham and P.D. Calvert, "The Physical Chemistry of Oxidation and Stabilisation of Polyolefins," in Development in Polymer Stabilization, Vol. 3, G. Scott, Ed., Applied Science Publishers, London, Chap. 5, 139-190 (1980).

34. X. Colin, J. Verdu, and B. Rabaud, unpublished results.

35. T.P. Gandek, T.A. Hatton, and R.C. Reid, Ind. Eng. Chem. Res., 28, 1036 (1989).

36. M. Denberg, E. Arvin, and O. Hassager, J. Water Supply: Res. Technol. Aqua, 56, 435 (2007).
37. G. Mittelman, J.H. Davidson, S.C. Mantell, and Y. Su, Sol. Energy, 82, 452 (2008).

38. G. Durliat, Bull. Union Phys., 91, 451 (1997).

39. J.P. Dear and N.S. Mason, Proc. Inst. Mech. Eng. Part L: J. Mater.: Design Appl., 220, 97 (2006).

40. G. Holst, Chem. Rev., 54, 169 (1954).

41. E. Gaudichet-Maurin and F. Thominette, J. Membr. Sci., 282, 198 (2006).

42. C. Causserand, S. Rouaix, J.-P. Lafaille, and P. Aimar, Chem. Eng. Process., 47, 48 (2008).

43. H.D.W. Roesink, Microfiltration Membrane Development and Module Design, PhD Thesis, University of Twente, The Netherlands (1989).

44. K. Fukatsu and S. Kokot, Polym. Degrad. Stab., 72, 353 (2001) 